\title{
QUEM GANHOU AS ELEIÇÕES? A VALIDAÇÃO DOS RESULTADOS ANTES DA CRIAÇÃO DA JUSTIÇA ELEITORAL
}

Paolo Ricci

\author{
Jaqueline Porto Zulini
}

\begin{abstract}
RESUMO
O presente artigo revisita a Primeira República brasileira (1894-1930) para elucidar a dinâmica politico-partidária do contencioso eleitoral numa fase anterior à consagração da magistratura enquanto órgão proclamador da verdade das urnas, prerrogativa instituída somente com o Código de 1932. Recorremos à crítica dos protestos eleitorais e de suas refutações, quando existentes, apresentados por adversários políticos frente aos resultados dos escrutínios para a Câmara Federal - fontes ainda inéditas, disponíveis nos Diários e Anais da própria Casa legislativa. Os dados levantados mostram que, ao contrário da visão disseminada pela literatura, a degola das oposições não era usual, mas restrita a anos críticos, quando o situacionismo local não conseguia coordenar as disputas regionais pelo poder. Na maioria dos casos, o parlamento, que arbitrava sobre o reconhecimento dos seus diplomados, tendia a ratificar as escolhas adotadas a nível subnacional. Desta forma, o caso brasileiro alerta para o fato de não se poder ler a adoção de tribunais independentes como mera resposta à solução do contencioso político que ocorria no parlamento, bem limitado. Tal achado nos permite pensar, antes, o advento da Justiça Eleitoral dentro de um projeto de reforma política mais ampla, incluindo a defesa de mecanismos democráticos para as eleições e que antecedem a validação dos votos.
\end{abstract}

PALAVRAS-CHAVE: Justiça Eleitoral; representação política; Primeira República; degola.

\section{INTRODUÇÃO ${ }^{1}$}

Toda reflexão sobre a democracia prende-se basicamente em torno da existência de eleições livres, regulares, abertas e competitivas (SCHUMPETER, 1988; DAHL, 1997). Nessa seara, a credibilidade do pleito e a validade dos resultados eleitorais perfaz elemento definidor de avaliação do regime político. A maioria das democracias contemporâneas confere a um órgão jurídico independente dos poderes representativos o que chamamos de contencioso eleitoral, isto é, a solução das controvérsias sobre a regularidade dos escrutínios e a certificação dos resultados das urnas. O fenômeno não é recente. Entre o final do sécu-lo XIX e o começo do século XX, a tendência foi delegar tal tarefa para um corpo externo ao parlamento. Há, inclusive, consenso na literatura em associar a condição da confiabilidade do pleito à

\footnotetext{
1 Agradecemos os comentários instigadores oferecidos por Fernando Limongi, Jairo Nicolau, Renato Perissinotto, Matthew Taylor e Ana Backes às versões prévias deste trabalho, subvencionado pelo Conselho Nacional de Desenvolvimento Científico e Tecnológico (CNPq). Uma versão modificada deste artigo foi publicada no Journal of Latin American Studies. Agradecemos também aos pareceristas anônimos da Revista de Sociologia e Política.
}

existência da justiça eleitoral para suplantar a discricionariedade típica dos tribunais políticos, preservando, assim, a manifestação da vontade popular (PASTOR, 1999; MOZAFFAR \& SCHEDLER, 2002). No Brasil, a história não seria diferente. Segundo a visão dominante, a implantação da Justiça Eleitoral em 1932 teve a finalidade de dar garantia efetiva ao voto (SADEK, 1995; MARCHETTI, 2008), livrando a apuração final de qualquer interferência da política partidária (LEAL, 1997).

Apesar do despertar recente dos estudiosos sobre o tema da governança eleitoral (MOZAFFAR \& SCHEDLER, 2002; LYONS, 2004), o estudo do contencioso em si e, em particular, sobre a administração dos escrutínios em época em que a justiça eleitoral ainda não havia sido adotada ficou limitado a estudos de caso ${ }^{2}$. Tudo considerado, nosso conhecimento limita-se à constatação de que, no século XIX, as próprias câmaras legislativas - tanto na América Latina como na Europa - eram as últimas instâncias competentes no reconhecimento dos diplomas e, portanto, decidiam definitivamente sobre

\footnotetext{
2 Para a Costa Rica, ver Lehoucq e Molina (2002), sobre a França, Charnay (1964) e a respeito da Alemanha, Ziblatt (2009).
} 
a validade das eleições ${ }^{3}$. Esse modelo havia sido adotado inicialmente na Inglaterra desde o surgimento do parlamentarismo (OROZCO HENRIQUEZ, 2007) quando a Câmara dos Comuns evocou o controle sobre a verificação dos poderes e a validação dos mesmos como símbolo e tutela da própria independência até a reforma que, em 1868, transferiu a competência para o poder Judiciário 4 (FALCON, 1998). O protótipo foi sucessivamente endossado na França, em 1789, conservandose nas constituições consecutivas de 1793 e 1795, e posteriormente incorporado à maioria das cartas magnas elaboradas na Europa em princípios do século XIX, a exemplo da alemã e da espanhola, para citar alguns ${ }^{5}$. Pode-se reconhecer nesse arquétipo a concepção montesquieuniana da separação dos poderes como defesa dos órgãos representativos da intervenção do monarca.

A questão do controle político sobre os resultados eleitorais levanta um problema central para o pesquisador. Trata-se de entender os mecanismos reais da tomada de decisão nas instâncias representativas sobre as eleições e, especialmente, a diplomação dos candidatos. Margaret Anderson, ao ilustrar o caso alemão, esclarece bem esse ponto ao afirmar que "when parliament has the authority to invalidate elections, a possibility always exists that the majority will use that authority to achieve what it could not accomplish on the hustings" (ANDERSON, 2000, p. 32) ${ }^{6}$. Recentemente, Fabrice Lehoucq (2003) também afirmou que a estabilidade dos regimes em voga no século XIX dependia tanto da organização das eleições (margem para fraude, manipulação e violência) quanto de como os poderes Executivo e Legislativo controla-vam os resultados eleitorais. A seu ver, a ausência de uma justiça eleitoral imparcial, uma oposição mantida constantemente fora das instituições representativas e um Executivo manipulador dos procedimentos administrativos "to impose their successors on the presidency and to create pliant legislative majorities" (idem, p. 32) 7 eram fatores críticos, capazes de gerar crises políticas que

\footnotetext{
3 Sobre as causas da passagem para um modelo que transfere ao poder Judiciário a decisão de validar os diplomas, ver Lehoucq (2003).

4 É o que estabeleceu The 1868 Parliamentary Elections Act.

5 Argentina, Bélgica, Estados Unidos e Itália ainda mantêm o controle político na condução do contencioso eleitoral - ao menos para as eleições legislativas nacionais.

6 "Quando o parlamento tem autoridade para invalidar as eleições, sempre existe a possibilidade de que a maioria use essa autoridade para obter o que ela não poderia realizar na campanha" (NR).

7 "Para impor seus sucessores sobre a presidência e para criar maiorias legislativas flexíveis" (NR).
}

ameaçavam a estabilidade do regime.

$\mathrm{O}$ artigo tem o propósito de investigar o papel do parlamento no exercício do rule adjudication, isto é, na solução dos litígios na disputa das eleições, o que é denominado, de acordo com a tradição francesa, de verificação de poderes (OROZCO HENRIQUEZ, 2007). Nessa perspectiva, o caso brasileiro torna-se interessante para especificar melhor a afirmativa de que esse modelo de solução das contendas eleitorais implicaria instabilidade política. O estudo focará a experiência da Primeira República, abarcando as os escrutínios federais ocorridas entre 1894 e 1930. Os dados revelam que, no país, a capacidade de filtrar a própria composição do parlamento por meio da verificação dos poderes conferiu estabilidade política ao regime republicano em momentos de crise - e não o contrário. Isso ficará evidente quando mostraremos a predominância dos casos de não reconhecimento de diplomas por parte da Câmara dos Deputados em situações caracterizadas pela presença de mais legisladores diplomados frente ao número previsto por lei, fazendo-se compulsória a decisão da Casa sobre a validade dos diplomas em excesso. A depuração consistia em uma decisão política a ser tomada em presença de um pleito eleitoral instável; fato que, na prática, sinaliza o caráter estratégico do controle exercido pelo governo sobre a certificação dos votos, mobilizado apenas em situações críticas.

Justamente em função desses novos achados para o caso brasileiro, acreditamos ser prudente a consideração do papel da verificação dos diplomas na construção de quaisquer modelos interpretativos da política vigente nos regimes do século XIX. Tal mecanismo deve ser pensado menos como prática fraudulenta finalizada a mudar o resultado eleitoral e mais como um ulterior elemento institucional a afetar, em última instância, a estabilidade política dos regimes em vigor naquele período.

\section{O CONTENCIOSO ELEITORAL NO BRASIL REPUBLICANO: ASPECTOS FORMAIS}

Esta seção descreve o processo de verificação dos poderes na Câmara dos Deputados à luz das regras previstas no regimento da Casa e nas leis eleitorais. Convergindo com o estatuído na maioria das constituições outorgadas no final do século XIX, a decisão final sobre os eleitos durante a Primeira República brasileira constituía competência ex officio do parlamento. Como tal, era alvo de freqüentes denúncias sobre a falta de imparcialidade na solução dos litígios eleitorais, motivando proposta de abandono da referida fórmula já em 1914. Todavia, o mecanismo partidário foi centralizado anos antes, em prol de regras mais claras, contrariando a literatura jurídica que tanto 
enfatiza a ausência de regulamentação no tocante aos procedimentos legislativos circunscritos à diplomação dos parlamentares.

Iniciemos pelo conjunto das normas eleitorais. A análise da dinâmica eleitoral durante a Primeira República mostra certa regularidade na ocorrência dos pleitos federais. Após a Assembleia Constituinte de 1891, a primeira eleição para a escolha dos representantes de Câmara e Senado ocorreu em 1894, repetindose a cada três anos até a Revolução de $1930^{8}$. No caso específico da Câmara Baixa, a Constituição de 1891, capítulo II, informava de maneira genérica que "o número de deputados será fixado por lei em proporção que não excederá de um por setenta mil habitantes, não devendo esse número ser inferior a quatro por Estado" (art. 28), deixando, portanto, ao legislador ordinário o poder de definir legalmente a matéria. Apesar de várias intervenções em torno da legislação eleitoral, deve-se ressaltar o fato de que, nessa época, a composição desta Casa não variou, fixando-se em 212 o número de deputados federais ${ }^{9}$.

Até a Lei Rosa e Silva, aprovada em 1904, os estados eram divididos em distritos eleitorais de três deputa- dos, respeitando quanto mais possível o critério da proporcionalidade. Os estados que elegiam até cinco deputados constituíam um único distrito. Quando o número de deputados não fosse divisível por três, para a formação dos distritos, a fração que excedia vinha a juntar-se ao distrito da capital. Assim, por exemplo, o Ceará, que elegia dez deputados, possuía três distritos, cada um deles com três deputados, menos o da capital, cujo número era de quatro. Com a promulgação da Lei n. 1269 de 15 de novembro de 1904, mais conhecida como Lei Rosa e Silva, determinou-se uma nova redistribuição dos distritos por estado. Conforme a nova lei os estados que elegiam até sete deputados constituíam um distrito único. Nos demais casos, os distritos passavam a eleger cinco deputados. Se o número de deputados não fosse divisível por cinco, juntava-se a primeira fração ao distrito da capital do estado e as eventuais frações restantes ao segundo distrito. A Tabela 1 resume essas mudanças, por estado ${ }^{10}$. Como se vê, São Paulo e Minas Gerais detinham, sozinhos, $28 \%$ das cadeiras na Câmara. Quando considerados os outros estados mais importantes, em termos de população e força econômica, como Bahia, Rio Grande do Sul e Pernambuco, o percentual sobe para $54 \%$.Goiás

TABELA 1 - NÚMERO DE DISTRITOS E DEPUTADOS POR UNIDADE FEDERATIVAE LEI ELEITORAL

\begin{tabular}{|c|c|c|c|c|}
\hline \multirow{2}{*}{ Estados } & \multicolumn{2}{|c|}{ Lei eleitoral de 1892} & \multicolumn{2}{|c|}{ Lei eleitoral de 1904} \\
\hline & Distritos & Deputados & Distritos & Deputados \\
\hline Minas Gerais & 12 & 37 & 7 & 37 \\
\hline São Paulo & 7 & 22 & 4 & 22 \\
\hline Bahia & 7 & 22 & 4 & 22 \\
\hline Rio de Janeiro & 5 & 17 & 3 & 17 \\
\hline Pernambuco & 5 & 17 & 3 & 17 \\
\hline Rio Grande do Sul & 5 & 16 & 3 & 16 \\
\hline Distrito Federal & 3 & 10 & 2 & 10 \\
\hline Ceará & 3 & 10 & 2 & 10 \\
\hline Pará & 2 & 7 & 1 & 7 \\
\hline Maranhão & 2 & 7 & 1 & 7 \\
\hline Alagoas & 2 & 6 & 1 & 6 \\
\hline Paraiba & 1 & 5 & 1 & 5 \\
\hline Piauí & 1 & 4 & 1 & 4 \\
\hline Sergipe & 1 & 4 & 1 & 4 \\
\hline Rio Grande do Norte & 1 & 4 & 1 & 4 \\
\hline Paraná & 1 & 4 & 1 & 4 \\
\hline Santa Catarina & 1 & 4 & 1 & 4 \\
\hline Goiás & 1 & 4 & 1 & 4 \\
\hline Amazonas & 1 & 4 & 1 & 4 \\
\hline Espírito Santo & 1 & 4 & 1 & 4 \\
\hline Mato grosso & 1 & 4 & 1 & 4 \\
\hline Total & 63 & 212 & 41 & 212 \\
\hline
\end{tabular}

FONTE: Lei n. 35, de 26 de janeiro de 1892 e Lei n. 1 269, de 15 de novembro de 1904. Elaboração própria dos autores.

\footnotetext{
8 Enquanto a legislatura tinha duração de três anos em o Congresso Nacional, o Presidente da República era eleito diretamente a cada quatro anos.

${ }^{9}$ São cerca de 40 as leis e decretos publicados entre 1890 e 1930 que regulamentam o processo eleitoral. As mudanças introduzidas
}

ao longo do tempo afetaram aspectos da organização dos escrutínios como a qualificação do eleitor, o alistamento e os títulos eleitorais, o próprio processo eleitoral e a apuração geral da eleição assim como os possíveis casos de crimes políticos.

10 Para um panorama geral em torno da evolução do sistema eleitoral brasileiro, ver Nicolau (2012). 
A unidade territorial imediatamente inferior ao distrito era o município. Cada município era sucessivamente dividido em seções nas quais se faziam as eleições e-eis o ponto que nos interessa-, encerrada a votação, eram inicialmente apurados os votos. No caso, o presidente ou quem o substituía, auxiliado pelos escrutinadores, abria a urna e apurava os votos dados aos candidatos cujo resultado era transcrito na ata da secção. Uma cópia da ata, após lavrada, era enviada ao presidente do governo municipal na sede de cada circunscrição eleitoral. Aqui, o presidente do governo municipal, os cinco candidatos mais votados e os cinco imediatamente menos votados passavam a uma nova apuração dos votos. O resultado das eleições era transcrito na ata geral da apuração, que continha não apenas a ordem de votação dos candidatos, mas também as reclamações e os protestos apresentados durante os trabalhos da Junta ou perante as mesas de cada seção. A importância da ata geral compreende-se à luz do dispositivo legal presente nas leis eleitorais, em que se afirmava que ela era remetida aos candidatos eleitos "para lhe servir de diploma"11. Essa é a característica distintiva do processo de apuração dos votos durante a Primeira República.

Com a Lei n. 3 207, de 27 de dezembro de 1916, a apuração geral das eleições passou a ser feita na capital do estado (art. 24). Uma inovação importante foi a de que a presidência da Junta Apuradora não era mais do presidente do governo municipal, mas agora era do juiz federal auxiliado na apuração pelo representante do Ministério Publico junto ao Tribunal Superior de Justiça. Como apontado por muitos analistas, esse era o primeiro passo em direção do reconhecimento do poder Judiciário como autoridade incumbida de apurar as eleições; prerrogativa introduzida somente a partir da publicação do Código Eleitoral de 1932 (PORTO, 2002; VALE, 2011) ${ }^{12}$. Assim, até fins da Primeira República pode-se afirmar, à guisa de conclusão, que a fase de apuração dos votos sempre seguiu um procedimento altamente descentralizado.

\footnotetext{
11 Com a Lei n. 3 207, de 27 de dezembro de 1916, a apuração geral das eleições passou a ser feita na capital do estado. A lei inovava estabelecendo que a presidência da Junta Apuradora fosse entregue a um juiz federal, auxiliado na apuração pelo representante do Ministério Público junto ao Tribunal Superior de Justiça.

12 Walter Costa Porto, porém, considera negativo esse ensaio de 1916 por gerar "graças às intervenções indébitas que desmoralizaram as apurações e os reconhecimentos de poderes, descrença em que os magistrados pudessem servir de garantia a uma boa representação, à expressão da verdadeira eleição popular" (PORTO, 2002, p. 254).
}

Após o encerramento dos trabalhos das Juntas Apuradoras é que se iniciava a segunda e última fase do processo de apuração das eleições, fase esta que, porém, era reservada à Câmara dos Deputados. A própria Constituição de 1891 era clara nesse ponto. O artigo 18 recitava que "a cada uma das câmaras compete certificar e reconhecer os poderes de seus membros". Aqui, os próprios parlamentares pronunciavam um juízo definitivo sobre os diplomas expedidos pelas Juntas Apuradoras assim como resolviam eventuais contestações e protestos e, em geral, qualquer reclamação apresentada durante a apuração dos votos. Era o chamado terceiro escrutínio, após o voto e o que cabia às Juntas Apuradoras ${ }^{13}$.

O terceiro escrutínio aparece geralmente na literatura como um processo circunscrito à comissão denominada, de maneira genérica, de "comissão de verificação de poderes", única responsável pelo exame dos diplomas. O processo, na realidade, era mais complexo, subdividindo-se em duas fases. Na primeira delas, os diplomas apresentados pelos candidatos passavam pelo crivo da "Comissão dos Cinco" - assim denominada porque composta por cinco membros nomeada pelo presidente provisório da Câmara. A partir da lista de diplomas apresentados pelos próprios deputados, essa comissão organizava uma primeira lista de diplomas, considerados legítimos, e que aparentemente revestiam as condições legais. A lista, para ter validade, precisava ser aprovada pelo plenário. Tratando-se de sessões preparatórias, não havia ainda um plenário legalmente constituído. Nesse ponto, mostrando certo maquiavelismo, o regimento da Câmara era bem claro: apenas os candidatos constantes da lista apresentada pela Comissão dos Cinco podiam participar da votação de plenário ${ }^{14}$. Portanto, eram os deputados previamente reconhecidos pela Comissão dos Cinco que aprovavam seus próprios diplomas! Esses deputados adquiriam o direito de participar da fase sucessiva, assim como de debater e deliberar no plenário durante as sessões preparatórias. A segunda fase iniciava-se quando os parlamentares legalmente reconhecidos pela Comissão dos Cinco eram sorteados para compor as Comissões de Inquérito, cujas funções

\footnotetext{
13 É importante lembrar que a mesma Constituição imperial de 1824 previa a verificação dos poderes observando-se o acordo com os regimentos internos de cada Casa. Foi nesses termos, inclusive, que o processo ocorria durante o Império.

14 Não se pense que essa seja uma característica do reconhecimento dos poderes apenas do Brasil. A necessidade de alcançar um quorum mínimo a partir do qual os parlamentos começavam seus trabalhos era uma característica de outros países, como França e Itália.
} 
eram as de relacionar a totalidade dos diplomas por estado, analisar as contestações e as reclamações e, em última instância, formular os pareceres em torno dos diplomas expedidos pelas Juntas Apuradoras, além de, eventualmente, dissentir da escolha feita pela Comissão dos Cinco $^{15}$.

Frente a tamanho arranjo formal, não é particularmente difícil entender que o momento crucial do inteiro processo de reconhecimento dos diplomas dentro da Câmara era o que se dava inicialmente na Comissão dos Cinco. Tal comitê agia como primeira instância de decisão dentro do parlamento. Como afirmou José Vieira em um relato apaixonado da sessão legislativa de 1909, "os cincos escolhidos passaram a possuir, para alguns candidatos, qualidade sobrehumana" (VIEIRA, 1980, p. 57). Ou seja, o momento político de maior importância não era tanto a análise dos diplomas nas Comissões de Inquérito, com as possíveis aberturas para o debate e o espaço de deliberação deixado aos oposicionistas, mas a escolha dos cinco membros que compunham a Comissão dos Cinco e, conseqüentemente, o critério adotado para declarar um diploma como legítimo. Cumpre reconhecer o fato de que, no início, uma comissão composta por cinco membros definia quais deputações eram legais e, por extensão, quais deputados iriam compor as Comissões de Inquérito, reduzindo severamente a possibilidade das forças oposicionistas serem legalmente reconhecidas e, ao mesmo tempo, a chance de ter contraditório amplo durante a deliberação na Comissão de Inquérito.

Entretanto, até a reforma de 1899, o regimento interno mostrava-se pouco funcional a uma lógica que permitisse o controle sobre a verificação dos poderes por meio apenas do poder exercido pela Comissão dos Cinco. Dois fatores revelam esse aspecto. Por um lado, como visto acima, o regimento da Câmara conferia amplo poder discricionário ao presidente provisório ao estabelecer que ele nomeasse o referido comitê. Portanto, inevitavelmente, isso colocava em pauta o problema de sua escolha. De acordo com o disposto regimental aprovado em 1891, durante as sessões preparatórias a presidência da Câmara era ocupada pelo deputado "mais velho em idade, dentre os presentes", servindo-lhe de secretários "os quatro deputados que mais moços lhe parecerem"16. Decerto, tratava-se de

\footnotetext{
15 Não se admitia, porém, a participação do deputado na comissão incumbida de analisar as eleições do estado em que fora eleito. O número das Comissões de Inquérito foi de cinco até 1904, passando-se para seis com a mudança regimental daquele ano.
}

16 Cf. art. 1 do regimento de 1891. um dispositivo incapaz de garantir ao governo o domínio sobre a presidência da Câmara e, conseqüentemente, na seleção dos membros da Comissão dos Cinco já que o deputado mais velho não era em si garantia de apoio ao situacionismo. Como enfaticamente lembrado por Campos Sales, "a questão estava assim entregue a um certificado de idade. Não é preciso muita argúcia para figurar as inúmeras hipóteses de fraudes que poderiam ser sugeridas" (SALES, 1983, p. 120).

Por outro lado, o regimento era omisso quanto ao critério a ser adotado para definição do diploma legal já que estabelecia como tal "a cópia autêntica da ata da apuração geral assinada por todos os membros da Câmara ou Intendência Municipal que tiveram comparecido a esse ato" (art. 2 do regimento de 1891). Entretanto, no caso de duplicatas ou até triplicatas, isto é, quando os vencidos se apresentavam à Câmara com uma lista de diplomas aparentemente legais concorrentes a da lista dos vencedores nas eleições, o risco para a posição situacionista era o do reconhecimento de deputados da oposição. Sem critério formal para decidir a respeito do que seria um diploma legítimo e com uma Comissão dos Cinco selecionada pelo presidente mais velho, a possibilidade de o governo controlar o processo de verificação era drasticamente diminuída. A implicação era a de que, especialmente em caso de conflito entre as forças políticas, a Câmara podia constituir-se por forças que se achassem em antagonismo com o governo.

Essa situação manifestou-se com toda sua força no final do século, em 1898, em ocasião da cisão na Câmara entre os "concentrados", ligados a Francisco Glicério, antigo dirigente do Partido Republicano Federal, e os "republicanos", fiéis a Prudente de Moraes. Com a proximidade das eleições de 1899, para a legislatura 1900-1903, a questão tornara-se propriamente eleitoral, na medida em que cada grupo buscava a vitória em cada estado (BEIGUELMAN, 1973; BACKES, 2006). Não é particularmente difícil imaginar o dissenso inevitável que se geraria por ocasião da instalação da nova Câmara em virtude das duplicatas e triplicatas de diplomas que apareceriam indicando a tentativa de cada corrente diplomar seus candidatos. Qual seria o critério a ser adotado pela Comissão dos Cinco para selecionar a lista dos diplomas legítimos? É nesse instante que o Presidente Campos Sales, eleito em 1898, conseguindo o apoio dos chefes estaduais mais importantes, manda aprovar uma pequena mudança no regimento, articulada na Câmara pelo deputado Augusto Montenegro. A reforma, mais conhecida como guilhotina Montenegro, estabeleceu que a presidência da Câmara durante os trabalhos preparatórios fosse ocupada pelo "presidente ou 
qualquer dos vice-presidentes que serviram na última sessão legislativa". Dessa forma, limitando-se a possibilidade de o presidente escolhido ser o mais velho apenas quando o presidente ou os vice-presidentes que serviram na última legislatura não terem sido eleitos, o governo não ficava mais sensível a eventuais presidentes hostis ou escassamente orientados com a posição situacionista. No caso em questão, a presidência era entregue ao deputado Vaz de Melo, representante de Minas cordial à política de Campos Sales.

A segunda mudança introduzida no regimento buscou definir mais claramente o que era diploma. Assim, entendeu-se "por diploma legítimo o documento que tiver sido expedido pela maioria da junta apuradora". A ênfase deve ser posta sobre o termo maioria. Não era uma mudança de pouco monta. Ao definir o que era um diploma legal, o legislador, na prática, vinculava a decisão da Comissão dos Cinco ao que já havia sido estabelecido pelas Juntas Apuradoras de cada distrito. Não há dúvida de que a mudança assim promovida não apenas confirmaria o caráter descentralizador do processo de verificação dos deputados, mas, sobretudo, o fato de que na Câmara era minimizada a possibilidade de influenciar tal processo. Desse modo, o papel da Comissão dos Cinco, assim como das Comissões de Inquérito, tornar-se-ia importante "apenas" no caso em que, efetivamente, o pleito eleitoral fosse tão confuso e competitivo que as oposições tinham como organizar duplicata e até triplicatas dos resultados eleitorais. A redefinição normativa do procedimento de verificação dos poderes interessou, portanto, seja à arena eleitoral, seja à parlamentar. Se, por um lado, foi formalizado o controle sobre a presidência provisória, por outro, atribuiu-se ao âmbito local, via Juntas Apuradoras, a competência na distribuição dos diplomas.

Tudo considerado, a literatura tem amplamente tratado da reforma de 1899. É notório que o resultado desse arranjo deu origem ao que ficou conhecido como "política dos governadores" ou, na expressão mais querida por Campos Sales, "política dos estados". Conforme as referências freqüentes à reforma regimental de 1899, embora ela afetasse apenas quatro artigos do regimento e fosse pensada para solucionar um problema de instabilidade política momentâneo, enfatiza-se o fato de que ela foi capaz de resolver as tensões políticas no âmbito federal. Ao reconhecer somente os diplomas dos eleitos pelo situacionismo local, independentemente do grupo político ao qual pertenciam, a reforma permitiu a cristalização da estrutura de dominação nos estados e a implantação das oligarquias estaduais (BELLO, 1954; SOUZA, 1973; CARDOSO, 1977; FAUSTO, 2005).
É curioso notar que, apesar da ênfase comum sobre a reforma, a literatura não ofereceu uma visão clara e definitiva em torno do lócus da degola17. Aqui, prevalecem duas interpretações. Para alguns, dá-se maior ênfase para a primeira parte da reforma, relativa ao critério para a escolha do presidente provisório, deixando de analisar a segunda parte da reforma que caracteriza o diploma em função da decisão majoritária da Junta Apuradora. Por exemplo, José Murilo de Carvalho afirma que "quem definia a apuração dos votos e reconhecia os deputados era o próprio Congresso em acordo com o presidente da república" (CARVALHO, 2005, p. 136). Na sua História do Brasil, Boris Fausto não deixa de sublinhar como único elemento decisório imposto pela reforma o do presidente da Câmara que influía na composição da comissão de verificação de poderes de acordo com sua fidelidade ao governo federal (FAUSTO, 2003, p. 259). O mais representativo crítico do sistema eleitoral da época, Assis Brasil, chegou a afirmar que "a eleição passou a ser mera formalidade. [...] O reconhecimento substituiu-se à eleição. E que reconhecimento! As crônicas autênticas da época, as próprias atas dos corpos legislativos exibem casos de se fazer um representante da nação por simples emenda, mandando trocar um nome por outro" (ASSIS BRASIL, 1990, p. 140). Essas afirmações acabam por fornecer uma visão do fenômeno do reconhecimento dos poderes que se inicia e termina no âmbito parlamentar. O significado real da mudança no regimento de 1899 é, portanto, limitado, já que a ênfase recai unicamente sobre a primeira parte da reforma, relativa ao critério para a escolha do presidente provisório da Câmara.

Outros autores minimizam a importância do processo de análise dos diplomas no Congresso e aceitam a interpretação de que tudo era decidido localmente. Lessa defende essa posição, afirmando que "as eleições já vem praticamente decididas, antes que a Comissão delibere a respeito dos reconhecimentos"

17 Enfocamos esse aspecto, por ser o objetivo do nosso trabalho. Na verdade há outras questões ainda menos consensuais que deveriam ser consideradas quando se pretende compreender a natureza da política dos governadores. Uma das questões recentemente debatidas diz respeito a como Campos Sales conseguiu encontrar apoio para aprovar a reforma no Congresso. Discordando da visão tradicional, que considera como determinante o diálogo iniciado entre o então Presidente da República e os governadores dos estados mais importantes, Ana Backes tem argumentado, de modo convincente, que o acordo passou também por uma articulação política interna ao Congresso. No caso, o pacto em questão não foi apenas entre alguns governadores, mas com os republicanos históricos em torno de um programa nacional cujo objetivo definido era a modernização do país. Para mais detalhe, ver Backes (2006). 
(LESSA, 1988, p. 106). Alcindo Guanabara, político e jornalista da época, resume bem esta interpretação em sua obra clássica, A presidência Campos Sales:

“A ‘comissão dos cinco', nomeada pelo Presidente, que já estava designado de antemão, não tinha mais senão que arrolar como líquidos os candidatos que apresentassem os diplomas assim assinados, quaisquer que fossem, aliás, as contestações que os acompanhassem. [...] Assim, o eixo do pleito eleitoral foi deslocado. Já não se tratava de garantir o presidente provisório a uma das parcialidades a fim de que dele se obtivesse uma 'comissão dos cinco' capaz de eliminar os diplomas líquidos dos adversários. A importância dessa comissão, que seria, no fim das contas, no regime anterior, a grande eleitora da Câmara, estava consideravelmente reduzida. O êxito da eleição dependia agora quase decisivamente de assegurar cada parcialidade a maioria das juntas apuradoras, para obter delas que rejeitassem as contestações oferecidas e assinassem em maioria, como límpidos e cristalinos, os diplomas dos seus correligionários" (GUANABARA, 2002, p. 7879).

Essas palavras indicam que o processo de verificação dos poderes deve partir inevitavelmente da dinâmica seletiva que se deu no âmbito local, anteriormente ao terceiro escrutínio ${ }^{18}$. A nosso entender, ambas as interpretações são válidas e não devem ser vistas como concorrentes. A centralização do processo de verificação dos poderes é inquestionável, mas sem levar em conta o papel das Juntas Apuradoras locais a interpretação fica restrita aos escândalos do reconhecimento que ocorriam no Congresso. Como veremos logo a seguir, a reconstrução do procedimento de verificação dos poderes durante a Primeira República não pode limitar-se ao conhecimento do que se passava no âmbito parlamentar, no exame das escolhas feitas pela Comissão dos Cinco antes e, sucessivamente, no trabalho das Comissões de Inquéritos, mas deve abranger o estudo do processo eleitoral como um todo. O processo de verificação de

18 “A confirmação da importância da medida que qualificou válidos os diplomas constantes das atas assinadas pela maioria das Juntas Apuradoras pode ser encontrada na reforma do regimento da Câmara de 1904. Isto porque tal mudança eliminou o disposto introduzido em 1899 , onde se especificava como diplomas legais somente os expedidos pela maioria da Junta Apuradora do distrito, ficando em seu lugar a disposição genérica pela qual se entenderia "por diploma o título ou documento [...] como tal for definido pela lei eleitoral vigente ao tempo em que se procedeu à eleição para a nova legislatura" (art. 16). Logo após a reforma regimental, o Congresso Nacional aprovou outra lei eleitoral, mais conhecida como Lei Rosa e Silva. Ao contrário das normas anteriores, a nova lei estabeleceu que "considerarse-á diploma a cópia autêntica da ata geral da apuração, assinada pela maioria dos membros da Junta que tiverem (?) funcionado", sendo que, no caso de duplicata de apuração, "reputar-se-á simples contestação a que for assinada pela minoria da junta" (art. poderes na Câmara apresentava-se, portanto, não como uma etapa alternativa ao momento eleitoral, mas como sucessiva a ela. É nesses termos que deve ser entendido o mecanismo de reconhecimento dos poderes e é dessa forma que o estudaremos nas seções a seguir.

\section{A CERTIFICAÇÃO DOS VOTOS: ALGUNS DADOS}

Há mais de 80 anos do fim da Primeira República, a percepção sobre o processo de verificação de poderes persiste a mesma ainda hoje: tratar-se-ia de mais um processo fraudulento, típico da dinâmica eleitoral republicana, por meio do qual se excluíam eventuais oposições, caracterizando o que viria a ser reconhecida como prática sistemática da depuração ou degola. Algo que seria corrigido apenas com a introdução da justiça eleitoral. Seguindo essa linha interpretativa, portanto, entende-se por degola a não aprovação, e a conseqüente não diplomação, pelas comissões de reconhecimento da Câmara de Deputados, de candidatos que as Juntas Apuradoras julgavam eleitos ${ }^{19}$.

Apesar de o mecanismo de verificação dos poderes representar um coro uníssono na literatura, por meio do qual, nas palavras de Lessa, "a República encontrou sua rotina" (LESSA, 1988, p. 111), é surpreendente constatar a inexistência de estudos que detalhem seu funcionamento e seus efeitos reais. As evidências que temos sobre a prática da degola são, de fato, decisivamente escassas. Todos os autores, sem exceção, limitam-se a citar casos notórios de deputados degolados assumindo, assim, que eles são representativos do fenômeno. Basta citar, aqui, a obra de referência para o período, A República Velha, de Edgar Carone, em que o autor lembra o que enfaticamente considerou "o grande escândalo,

102). Como se vê, a norma fixada no regimento para o reconhecimento dos diplomas saiu deste corpo de regras interno à casa legislativa para adentrar na lei eleitoral. Ficamos, então, com a sensação de que o equilíbrio formal encontrado por Campos Salles em 1899 via reforma regimental vinha a ser agora estendido ao âmbito dos próprios escrutínios, fazendo-se agora previsto na lei eleitoral".

19 A definição é a mesma de Walter Porto, em seu Dicionário do Voto (PORTO, 2000), com uma diferença substantiva. O autor define a degola como "a não aprovação, e a conseqüente não diplomação, pelas comissões de reconhecimento do Senado e da Câmara de Deputados, de candidatos que a opinião pública julgava eleitos" (PORTO, 2000, p. 157). A ênfase na opinião pública é, a nosso entender, equivocada. De acordo com a lei eleitoral o diploma oficial, legalmente válido, era aquele expedido pela Junta Apuradora local e não certamente o que a opinião pública indicava. Por essa razão, enfatizamos na definição acima o aspecto que remete ao papel das Juntas Apuradoras. 
escândalo imortal" (CARONE, 1972, p. 307) da Paraíba, a saber: o episódio da depuração liderada por Campos Sales, degolando todos os candidatos oficialmente eleitos a fim de reconhecer os políticos fiéis ao seu então ministro Epitácio Pessoa. Para Carone, tal exemplo parecia-lhe suficiente para embasar afirmações mais genéricas, sugerindo mesmo que as arbitrariedades repetiram-se nos anos seguintes até 1930. Não há livro ou artigo de periódico em que não se ressalte a possibilidade da manipulação da representação popular expressar-se, para além dos clássicos mecanismos eleitorais, por meio do processo de reconhecimento dos poderes ${ }^{20}$.

A principal limitação desse raciocínio é, sem sombra de dúvida, a ausência de evidências contundentes em defesa da suposta alta freqüência com que a depuração teria se manifestado no período. O questionamento não é de pouca monta. Afinal, não sabemos quão representativas do problema seriam as citações extraídas de várias fontes, em que pese uma tentativa de enumeração das degolas. Como bem observou Ian Lustick, as interpretações de um fenômeno "could just as well be based on the errors, biases, interpretations, omissions, and exaggerations produced by errant historians, as on reliable reports of past political or social realities" (LUSTICK, 1996, p. 605)21. A Tabela 2 , a seguir, aponta o dado relativo ao volume das degolas. De acordo com a definição de degola adotada anteriormente, foi considerado degolado o candidato cujo diploma expedido pela Junta Apuradora não era reconhecido na Câmara dos Deputados ${ }^{22}$.

TABELA 2 - NÚMERO DE DEPUTADOS DEGOLADOS, POR ANO ELEITORAL (1894-1930)

\begin{tabular}{|l|c|c|c|}
\hline Ano eleitoral & Número de deputados & Número de diplomas recebidos & Diferença (degola) \\
\hline 1894 & $188^{1}$ & 196 & +8 \\
1897 & 212 & 224 & +12 \\
1900 & 212 & 290 & +78 \\
1903 & 212 & 225 & +13 \\
1906 & 212 & 227 & +15 \\
1909 & 212 & 224 & +12 \\
1912 & 212 & 252 & +40 \\
1915 & 212 & 274 & +62 \\
1918 & 212 & 216 & +4 \\
1921 & 212 & 220 & +8 \\
1924 & 212 & 220 & +8 \\
1927 & 212 & 212 & 0 \\
1930 & 212 & 212 & 0 \\
Total & 2732 & 2992 & $\mathbf{2 6 0}$ \\
\hline
\end{tabular}

FONTE: Anais da Câmara dos Deputados (1894-1930). Elaboração própria dos autores, a partir dos Anais da Câmara dos Deputados e do Congresso Nacional"

NOTA: 1. Faltam os diplomas de Santa Catarina, Paraná e Rio Grande do Sul, que não chegaram à Câmara em virtude da Revolução Federalista.

20 Citações em tal sentido podem ser encontradas em obras clássicas como a de Victor Nunes Leal (1997, p. 256), Nicolau (2002, p. 34), Walter C. Porto (2004, p. 114) e Carvalho (2005, p. 136).
21 "Poderiam muito bem ser baseadas nos erros, inclinações, interpretações, omissões e exageros produzidos por historiadores errantes, bem como em relatos confiáveis de realidades políticas ou sociais passadas" (NR).

22 Neste artigo focamos as eleições para o cargo de deputado federal que ocorriam a cada três anos, desconsiderando eventuais eleições para substituir um deputado falecido ou desistente do cargo no decorrer da legislatura. 
Entre 1894 e 1930, 260 candidatos diplomados pelas Juntas Apuradoras foram degolados. O número de diplomas aprovados pelo processo de verificação foi de 2732. Ou seja, do total de 2992 diplomas que chegaram à Câmara, apenas $8,7 \%$ não foram reconhecidos. Em retrospectiva, levando em conta, sobretudo, o fato de que a literatura tenha continuamente enfatizado o processo de depuração dos diplomas oposicionistas, o valor de $8,7 \%$ não nos parece grande coisa. Basta olhar para o dado do ângulo oposto. Afinal, como interpretar os $91,3 \%$ de diplomas reconhecidos? Não há duvida de que nossa conclusão deveria acusar a inexistência daquela sistematicidade destacada pela maior parte dos trabalhos sensíveis à tese da ação direta da Câmara no volume de apurações totais como padrão da verificação de poderes durante a Primeira República ${ }^{23}$.

Outro aspecto surpreendente é ausência de degola em 1930. Isso contradiz a leitura feita por Edgar Carone e outros, que se tornou dominante, segundo a qual todos os cinco deputados da Paraíba e 14 de Minas Gerais teriam sido degolados (CARONE, 1971, p. 416). Importa ressaltar a exclusão dessa vivência mineira da nossa análise já que, naquela ocasião, único caso na história republicana, as Juntas Apuradoras locais mineiras não expediram diplomas, relegando à Câmara a decisão final. Claramente, sem duplicatas e diplomas emitidos, não se pode falar em degola dado que a Casa foi obrigada a posicionar-se a respeito do resultado eleitoral ${ }^{24}$. O caso da Paraíba é, porém, diferente. A leitura dos Anais evidenciou que a Comissão dos Cinco, antes, e a de Inquérito, depois, aceitaram, tout court, a decisão final da Junta Apuradora local que expediu diplomas a cinco deputados. Ou seja, se houve degola dos oposicionistas, isto ocorreu naquele âmbito e não na Câmara, como alguns estudiosos tendem a assumir. As palavras de um dos contestantes não deixam dúvidas em tal sentido. Segundo ele, a Comissão de Inquérito da Casa "ratificou as manobras fraudulentas da Junta Apuradora da Paraíba"25.

23 O único trabalho anterior a este que tentou sistematizar o
volume das degolas foi o de Maria C. M. Cortez (1986), no qual
se informa serem 301 os diplomas não reconhecidos na época. O
mais interessante a notar é que a autora não questiona o baixo
nível de diplomas degolados no período, ressaltando, aliás, o
fato de não ocorrerem degolas apenas em 1927 e 1930 .
24 Obviamente, isso não significa que naquela ocasião a escolha
dos eleitos não seguiu razões de natureza política. Sobre o caso
mineiro, ver o testemunho do próprio relator, Humberto de Cam-
pos (1954, v. 2, p. 24-26), que relata as pressões feitas pelo líder
da maioria para que favorecesse certos deputados.
25 Anais da Câmara, 28 de abril de 1930, p. 7539. Aponta na
mesma direção Walter Porto (2004, p. 114) que, citando as me-
Cumpre também salientar, porém, que a ênfase sobre o valor total dos diplomas degolados não é um bom indicador do fenômeno. De fato, como se observa na Tabela 2 , há uma alta concentração em alguns anos; mais precisamente em 1900, 1912 e 1915. As três eleições condensam $69,2 \%$ por cento das degolas totais registradas na Primeira República. Isto é, não apenas o nível das depurações é baixo, mas altamente concentrado. De certa forma, isso mostra que a reforma de 1899 não inventou uma prática no processo de reconhecimento dos poderes. Os dados para 1894 e 1897 , relativos às duas eleições anteriores à reforma de 1899 , mostram que o número de degolas é de fato similar ao de outros anos eleitorais, posteriores ao arranjo Campos Sales.

Vale ainda assinalar que a depuração não afetava todos os estados indiscriminadamente. Das 260 depurações registradas, $58,1 \%$ delas são concentradas na Bahia, Rio de Janeiro, Distrito Federal e Ceará. Nos estados mais importantes da federação - São Paulo, Rio Grande do Sul e Minas Gerais - as degolas foram de apenas $8,1 \%{ }^{26}$. É verdade, porém, que esses dados devem ser ponderados pelo número de deputados de cada estado. Amazonas e Goiás, por exemplo, elegiam apenas quatro candidatos. Para isso, calculamos o valor das degolas por estado a partir do total de diplomas concedidos pelas Juntas Apuradoras locais. Para uma melhor visualização dos dados, optamos por agrupar as degolas registradas em 1900, 1912 e 1915, distinguindo-as das demais.

mórias de João Neves da Fountoura, afirmara que as degolas ocorriam nos próprios estados.

26 A literatura considera esses estados importantes dado o papel estratégico que eles possuíam no jogo político republicano. Basta lembrar o consenso vigente entre os estados de que a escolha dos presidentes da república era uma decisão que interessava diretamente São Paulo e Minas Gerais. Para mais detalhes, ver os trabalhos clássicos de Joseph Love (1975; 1982), Eul Sôo Pang (1979), Robert Levine (1980), John Wirth (1982). 


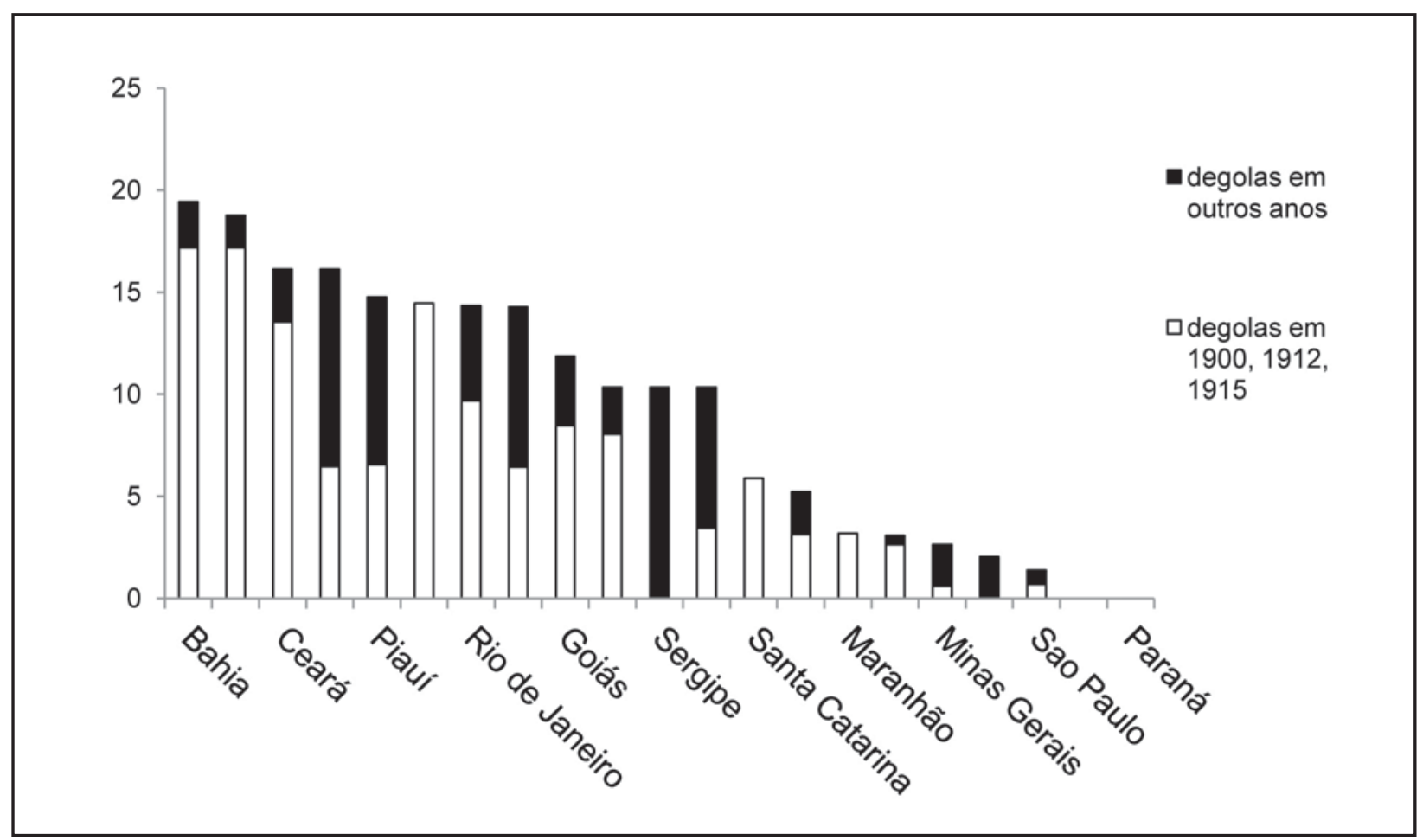

FONTE: Elaboração própria dos autores, a partir dos Anais da Câmara dos Deputados e do Congresso Nacional.

Como é possível facilmente observar no Gráfico 1, a degola foi um ato arbitrário que afetou de modo diferente as deputações estaduais. Consideremos primeiramente o valor total dos diplomas degolados por estado. Confirma-se o valor mais elevado para Bahia, Ceará, Distrito Federal e Rio de Janeiro. Aqui, em cada estado, mais de $15 \%$ dos diplomas foram depurados. Entretanto, o dado interessante refere-se à presença expressiva da degola em estados com número baixo de deputados, como Amazonas, Mato Grosso, Piauí e Paraíba. Considerando-se as depurações por ano eleitoral, notamos que há estados onde elas ocorreram predominantemente em outras épocas, não apenas em 1900, 1912 ou 1915. É o caso de Sergipe, Mato Grosso, Piauí, Espírito Santo e do Distrito Federal $^{27}$.

Passamos agora a considerar as razões que levaram o legislador a não reconhecer 260 diplomas. Será que elas seguem o mesmo padrão? Para elucidar esse aspecto, examinamos, nos Anais da Câmara, as justificativas formais que determinaram a degola. $\mathrm{Na}$ prática, duas eram as razões que conduziam a ela. A primeira era a presença de duplicatas. A Junta Apuradora

\footnotetext{
27 Para mais detalhes sobre as causas do nível elevado de diplomas não reconhecidos nos três anos acima indicados, ver Ricci e Zulini (2012).
}

distrital havia expedido mais diplomas do que o número de deputados previsto por lei. Às vezes, os registros dos debates denotam a organização de mais de uma Junta Apuradora local, cada uma diplomando uma chapa de candidatos, criando-se, portanto, duplicatas de diplomas. Eis a prova mais evidente da emergência de uma luta política acirrada no âmbito local, que o próprio governador, por meio da Junta Apuradora, não fora capaz de solucionar. Assim, nesse primeiro caso, a Câmara era obrigada a decidir sobre a validade dos diplomas em excesso. Ou seja, a degola era produto de uma ação forçada e necessária, dada a indecisão das instâncias inferiores.

A segunda razão remete a uma divergência manifesta entre a decisão tomada pela Junta e a da Câmara. Aqui, sem diplomas em excesso, era a própria Câmara, nas Comissões de Inquérito ou no plenário, que revertia a decisão tomada pela Junta Apuradora local, degolando um deputado nomeado e reconhecendo um candidato que havia apresentado uma contestação. O contestante, vestindo os trajes do político fraudado, apresentava inúmeros documentos, novas atas de seção, cartas de eleitores denunciando as fraudes no ato do voto, ou, ainda, argumentava pela inelegibilidade de outro diplomado e de outra chapa. Contestava-se tudo e a todos com o objetivo de demonstrar que ele mesmo e sua chapa política estavam legitimamente eleitos e que a Junta Apuradora havia-lhes atribuído o diploma legal. Às vezes, as contestações eram tão 
sofisticadas e detalhadas que o próprio contestante refazia os cálculos dos votos, apresentando o que argumentava ser a verdadeira lista dos eleitos e que, em sua maioria das vezes, representava a chapa oposicionista. Nesse processo, claramente, todos os diplomados perdiam votos, que eram remanejados na ordem da lista final, ou até viam-se excluídos. Essa segunda explicação da ocorrência da degola é relevante, já que indica claramente a inversão voluntária da decisão majoritária que havia ocorrido no âmbito local e, portanto, apontaria em direção da prática fraudulenta praticada no terceiro escrutínio.

Um exemplo ajuda-nos a esclarecer esse ponto. Caso notório de intervenção do Congresso foi a eleição do deputado Barbosa Lima, em 1915, para o primeiro distrito do Distrito Federal. Parlamentar desde 1890,
Barbosa Lima não havia alcançado boa votação no pleito de 1914, ficando em sétimo lugar, com 1188 votos - o último dos eleitos, o quinto colocado, havia obtido 2368 preferências. Apesar de não ter sido diplomado pela Junta Apuradora, assim como pela Comissão dos Cinco ou pela Comissão de Inquérito, Barbosa Lima conseguiu, graças à intervenção do líder do governo Antonio Carlos, apoio no plenário das bancadas de Minas Gerais e São Paulo - e acabou sendo diplomado ${ }^{28}$. Para verificar se o caso é representativo do fenômeno, ou mera exceção, identificamos as razões pelas quais ocorreram as 260 degolas anteriormente relatadas, diferenciando as depurações por duplicatas das degolas em razão do reconhecimento de candidatos contestantes. Os dados são reportados na tabela a seguir.

TABELA 3 - TIPO DE DEGOLAS, POR ANO ELEITORAL

\begin{tabular}{|l|c|c|c|}
\hline \multirow{2}{*}{ Ano eleitoral } & \multirow{2}{*}{ Total de degolas } & \multicolumn{2}{|c|}{ Motivação } \\
\cline { 3 - 4 } & & Duplicatas & Contestações \\
\hline 1894 & 8 & 5 & 3 \\
1897 & 12 & 10 & 2 \\
1900 & 78 & 72 & 6 \\
1903 & 13 & 9 & 4 \\
1906 & 15 & 5 & 10 \\
1909 & 12 & 6 & 6 \\
1912 & 40 & 29 & 11 \\
1915 & 62 & 56 & 6 \\
1918 & 4 & 0 & 4 \\
1921 & 8 & 3 & 5 \\
1924 & 8 & 1 & 7 \\
1927 & 0 & 0 & 0 \\
1930 & 0 & 0 & 0 \\
Total & 260 & 196 & 64 \\
\hline
\end{tabular}

FONTE: Anais da Câmara dos Deputados. Elaboração própria dos autores, a partir dos Anais da Câmara dos Deputados e do Congresso Nacional

Nota-se que, de maneira expressiva, são minoritárias as situações nas quais se registram o reconhecimento de contestantes por parte da Câmara. Do total de 486 contestações que pediam o reconhecimento de outro candidato e que coletamos por meio da leitura dos pareceres das Comissões de Inquérito, a Câmara - nas próprias Comissões de Inquérito ou no plenário - reverteu a situação em apenas 64 delas, reconhecendo o diploma aos contestantes. Isso representa $24,6 \%$ dos casos de degolas registradas no período. Nesse sentido, os casos de reversão da decisão tomada pelas Juntas Apuradoras eram, portanto, poucos, restritos a casos específicos, às vezes legitimando a escolha de um diploma por motivos pessoais, e não partidários. É evidente, então, que a degola como prática fraudulenta era diminuta e o verdadeiro problema para o poder verificador era principalmente a instabilidade da eleição local, que

28 Para mais detalhes, ver Afonso A. de Melo Franco (1973). 
resultava em duplicatas, obrigando o presidente da República e sua maioria na Câmara a expor-se publicamente conforme se fazia necessário e a tomar partido em favor de determinado grupo de candidatos. Dito de outra forma: o contencioso dava-se dentro de uma lógica que garantia a estabilidade do sistema político e não deve ser entendido como prática injustificada para mudar o resultado eleitoral. Por último, uma consideração em torno do lócus da decisão durante o exame dos diplomas no parlamento. Como exposto acima, o reconhecimento dos diplomas não se esgotava na Comissão dos Cinco, mas definia-se nas Comissões de Inquérito que avaliavam os documentos e eventuais protestos oferecidos aos diplomas expedidos pelas Juntas Apuradoras. Haveria dissonância entre o parecer da Comissão dos Cinco e o das Comissões de Inquérito? E, ainda, era o plenário condizente com a decisão tomada pela Comissão dos Cinco ou também ele a modificara no ato do voto final, na própria Câmara? Responder a essas perguntas é crucial já que nos permite entender a tramitação dos processos na Câmara e eventualmente questionar algumas interpretações dominantes. Nos textos historiográficos, por exemplo, são inúmeros os exemplos que contam detalhadamente as batalhas travadas ao redor do reconhecimento dos diplomas. Caso notório de divergência do plenário após a decisão da Comissão de Inquérito foi, por exemplo, o do caso da eleição do deputado Barbosa Lima, acima relatada. Para verificar se esse caso, como outros, são a regra ou a exceção, identificamos, então, eventuais situações de conflito e de cooperação existentes entre o parecer da Comissão dos Cinco e a decisão final, a ser tomada em plenário. Dos 2992 diplomas que chegaram à Câmara, cerca de $84 \%$ deles foram alvo de consenso entre as três instâncias decisórias - isto é, fizeram-se reconhecidos igualmente pela Comissão dos Cinco, pelas Comissões de Inquérito e pelo plenário. Em outros casos (cerca de 11\%), sobretudo quando havia duplicatas, a Comissão dos Cinco não tomava decisão no mérito dos diplomas dos deputados de um estado ou distrito delegando a decisão final à Comissão de Inquérito - deliberação ratificada, na seqüência, pelo plenário. Os casos de conflito - entre a decisão da comissão dos Cinco e as Comissões de Inquérito ou, também, frente o juízo final do plenário - eram poucos, menos de 5\%, restritos a situações específicas, às vezes legitimando a escolha de um diploma por motivos pessoais, e não partidários. Ou seja, o padrão decisório sobre a diplomação dos deputados era a cooperação entre as instâncias internas à Câmara.

\section{CONCLUSÕES}

$\mathrm{O}$ estudo aqui empreendido permite-nos avançar algumas conclusões em torno do processo de verificação dos poderes e, por extensão, ampliar nosso entendimento sobre o processo de reforma política que levou à implantação da Justiça Eleitoral em 1932. Em primeiro lugar, uma reflexão sobre a tomada de decisão na Câmara Federal. Os dados analisados apontam a Comissão dos Cinco, que filtrava as decisões iniciais, como o grande ponto de veto durante o processo decisório congressual. As demais instâncias decisórias - Comissões de Inquérito e plenário - tendiam a respeitar as deliberações aí tomadas. Isso confirma a tese defendida pela interpretação tradicional, que vê nela "a mais poderosa; a origem do poder verificador" (MELO, 1973, p. 722). Desse modo, o equívoco da visão dominante está em derivar da centralidade da Comissão dos Cinco a idéia de que, nas palavras de Raimundo Faoro, a degola era um ato que "ocupou o lugar das apurações" (FAORO, 1975, p. 628). Os dados mostram claramente que o reconhecimento dos diplomas na Câmara era, na verdade, a ratificação das escolhas ocorridas nos estados, por meio dos diplomas emitidos localmente. Em geral, a Comissão dos Cinco simplesmente "carimbava" a lista dos eleitos conforme definida no nível subnacional pelas Juntas Apuradoras. Essa última constatação leva-nos a defender a hipótese de que grande parte do processo de depuração ocorria, de fato, regionalmente, nas Juntas. A mesma afirmação foi feita por Renato Lessa, segundo o qual a Comissão dos Cinco "opera como garantia extra para impedir o acesso de inimigos ao parlamento" (LESSA, 1988, p. 106). Nesse contexto, apenas quando a oposição nos estados fosse forte a ponto de organizar-se e apresentar duplicatas e triplicatas é que o papel da Comissão dos Cinco tornar-se-ia central. Daí defendermos a revisão da interpretação convencional, que tende a focar apenas a dimensão parlamentar do processo de reconhecimento dos diplomas.

Os casos críticos de 1900, 1912 e 1915, mostrando que o terceiro escrutínio adquiriu naquelas ocasiões a força e a vitalidade que a maior parte dos autores atribui, sem distinção, a toda a Primeira República, permitemnos sugerir uma interpretação um pouco diferente. Inquestionavelmente, o pacto fortalece o regionalismo, estadualizando a representação política. Entretanto, é também verdade que deixa aberta a possibilidade de intervenção direta do presidente da República no parlamento, por meio do processo de verificação dos diplomas, já que o poder Executivo federal conta, a partir da reforma de 1899, com a garantia de um aliado na direção dos trabalhos legislativos na Câmara dos Deputados. Assim, sempre que os conflitos e as lutas políticas nos estados não eram resolvidos por meio 
dos mecanismos vigentes - como a fraude, a violência ou a cooptação política da oposição -, a verificação dos poderes tornava-se peça importante do mecanismo de reconhecimento dos diplomas. Fato esse que ocorreu majoritariamente em três eleições e em alguns estados. Confirma-se aqui, portanto, a tese minoritária de parte da literatura, embora demasiada perspicaz, que aponta como parcial a desnacionalização da competição política nos anos 1894-1930 (BACKES, 2006). Esse achado contradiz a interpretação recentemente ofere-cida por Lehoucq endossando o aumento da probabi-lidade da instabilidade política na inexistência de justiça eleitoral - delegando-se o reconhecimento dos poderes ao poder Legislativo - e quando "one agent can gain control of the executive and possess a large legislative majority" (LEHOUCQ, 2002 , p. 35$)^{29}$. O caso brasileiro mostra exatamente o contrário. Sugere, antes, que o mecanismo do reconhecimento dos poderes ativava-se em circunstâncias limitadas, quando a competição eleitoral e a luta política local - isto é, a própria instabilidade política - ameaçava o âmbito nacional e o monopólio do governo federal. Cabe a outros estudos averiguar se o mesmo processo servia como garantia de estabilidade do regime em outros países e em quais conjunturas o governo recorria ao mesmo.

Por fim, no que tange à imagem relativa ao reconhecimento dos poderes como prática fraudulenta, o estudo mostra que a degola não representava, como alguns têm afirmado, uma "garantia extra para impedir o acesso de inimigos ao parlamento" (LESSA, 1988, p. 106) ${ }^{30}$, já que era escassamente praticada. Os dados revelam, antes, que tal atitude fraudulenta era minoritária, sendo a degola mais o resultado da presença de duplicatas. Dito de outro modo: o contencioso político revelava-se pouco relevante quando considerada a fraude passível de desenrolar em outros momentos da etapa eleitoral (como a fase do alistamento, o dia do pleito em si ou, mesmo, o período de contagem dos votos). Talvez o governo tenha desestimulado a degola na Câmara pelo caráter altamente custoso dessa saída, já que pública, enquanto a distorção das preferências expressas no escrutínio ou a mera violência durante as eleições mostrassem-se menos visíveis perante a opinião pública. Como enfaticamente lembra Adam

\footnotetext{
29 "Um agente ganha controle do Executivo e possui uma larga maioria legislativa" (NR).

30 Na mesma direção ver também as reflexões feitas anos atrás por Maria D'Alva Kinzo (1980, p. 78-80), que apontava como o terceiro escrutínio funcionava para barrar eventuais dissidências que não tinham o apoio dos governadores e que, sustentadas por seus redutos coronelísticos, conseguiam enviar seus representantes.
}

Przeworski, "in almost all of its activity, fraudulent activity is secret" 31 (PRZEWORSKI, 2010, p. 119). Independentemente disso, cremos dever ser reduzida a interpretação da visão convencional da historiografia sobre a centralidade do mecanismo de reconhecimento dos poderes como mero ato fraudulento que modifica as escolhas dos eleitores. O erro dos estudiosos contemporâneos foi assumir justamente isso inferindo, quase que automaticamente dos testemunhos da época, o número elevado de degolas sem dar a devida ênfase ao seu uso estratégico. Um levantamento acurado do fenômeno, como o aqui realizado, refutaria cabalmente ledo engano ao mostrar como o contencioso eleitoral republicano adquiria a característica de momento decisório em que se confirmam as decisões adotadas no âmbito subnacional. Se a literatura ressalta a importância do conflito político ser resolvido em conformidade com os princípios da constitucionalidade e da legalidade, sem critérios amplamente discricionários de oportunidade e negociação política (OROZCO, 2012), deve-se constatar que, do ponto de vista prático, as decisões propriamente políticas, parlamentares, sobre a validade dos diplomas na experiência brasileira ficariam restritas a poucos episódios. A principal implicação desse achado é a importância do exame da fraude em todas as suas fases, isto é, tratando-a em função de três elementos - o momento pré-eleitoral, o da eleição e o pós-eleitoral.

Em suma, o caso brasileiro alerta para o fato de não se poder ler a adoção de tribunais independentes como mera resposta à solução do contencioso político, bem limitado. Isso abre espaço para pensar-se a Justiça Eleitoral dentro de um projeto de reforma política mais ampla, incluindo a defesa de mecanismos democráticos para as eleições e que antecedem a validação dos votos. Antes de 1930, o nosso entendimento sobre o processo de diplomação exige a admissão da existência de uma simbiose entre processo eleitoral e dinâmica parlamentar. Dito de outra forma, o sucesso eleitoral para o partido situacionista dependia desta simples equação: controle dos votos a nível local e, eventualmente, depuração na Câmara. Por isso acreditamos que seja necessário defender uma pesquisa sobre o período republicano, orientada para a compreensão das dinâmicas políticas locais dentro de uma perspectiva que, porém, leve em conta a articulação com o nível nacional. Repete-se freqüentemente que a Primeira República é o triunfo do localismo. Entretanto, sem um olhar atento para a relação entre o local e a dinâmica política nacional a interpretação final em torno desse período será sempre limitada e circunstanciada.

\footnotetext{
31 "Em quase toda a sua atividade, a atividade fraudulenta é secreta" (NR).
} 
Paolo Ricci (paolo.ricci@terra.com.br) é Doutor em Ciência Política pela Universidade de São Paulo (USP) e Professor do Departamento de Ciência Política da mesma universidade.

Jaqueline Porto Zulini (jaquepz@gmail.com) é Doutoranda em Ciência Política pela Universidade de São Paulo (USP).

\section{REFERÊNCIAS BIBLIOGRÁFICAS}

ANDERSON, M. L. 2000. Practicing Democracy: Elections and political culture in Imperial Germany. Princeton: Princeton University.

ASSIS BRASIL, J. F. 1990. Democracia representativa: do voto e do modo de votar. In: PINTO, P. B. S. (org.). Idéias politicas de Assis Brasil. Brasília: Senado Federal.

BACKES, A. L. 2006. Fundamentos da ordem republicana: repensando o Pacto Campos Sales. Brasília: Câmara dos Deputados.

BEIGUELMAN, P. 1973. Pequenos estudos de Ciência Politica. São Paulo: Pioneira.

BELLO, J. M. 1954. História da República. São Paulo: Nacional.

CAMPOS, H. 1954. Diário Secreto. 2 v. Rio de Janeiro: Cruzeiro.

CARDOSO, F. H. 1977. Dos governos militares a Prudente-Campos Sales. In: FAUSTO, B. (org.). O Brasil republicano. Tomo III. Rio de Janeiro: Bertrand.

CARONE, E. 1971. A República Velha. São Paulo: Difusão Européia do Livro.

. 1972. A República Velha. Instituições e Classes Sociais. São Paulo: Difusão Européia do Livro.

CARVAlHO, J. M. 2003. Cidadania no Brasil. O longo caminho. Rio de Janeiro: Civilização Brasileira.

2005. Pontos e Bordados. Escritos de historia e política. UFMG: Belo Horizonte.

CHARNAY, J. P. 1964. Les scrutins politiques en France de 1815 à 1962: contestations et invalidations. Paris: Fondation Nationale des Sciences Politiques.

CORTEZ, M. C. M. 1986. O mecanismo das comissões verificadoras de poderes. Estabilidade e dominação política, 1894-1930. Brasília. Dissertação (Mestrado em Ciência Política). Universidade de Brasília.

DAHL, R. 1997. Poliarquia, participação e oposição. São Paulo: USP.
FALCON, J. P. 1998. Algunas consideraciones sobre el control de las actas electorales en el derecho comparado y en la historia constitucional española. Revista de Estudios Políticos, Madrid, v. 99, n. 1, p. $175-178$.

FAORO, R. 1975. Os donos do poder: formação do patronato político brasileiro. São Paulo: Globo.

FAUSTO, B. 2003. História do Brasil. São Paulo: USP.

GUANABARA, A. 2002. A presidência Campos Sales. Brasília: Senado Federal.

KINZO, M. A. 1980. Representação Política e Sistema Eleitoral no Brasil. São Paulo: Símbolo.

LEAL, V. N. 1997. Coronelismo, enxada e voto. Rio de Janeiro: Nova Fronteira.

LEHOUCQ, F. 2002. Can Parties Police Themselves? Electoral governance and democratization. International Political Science Review, Thousand Oaks, v. 23, n. 1, p. 29-46, Jan. Disponível em: ht tp:// libres.uncg.edu/ir/uncg/f/ F_Lehoucq_Can_2002.pdf. Acesso em: 15.abr.2013.

. 2003. Electoral Fraud: Causes, types, and consequences. Annual Review of Political Science, Palo Alto, v. 6, p. 233-256, June.

LEHOUCQ, F. E. \& MOLINA, I. 2002. Stuffing the Ballot Box. Fraud, electoral reform, and democratization in Costa Rica. Cambridge (UK): Cambridge University.

LESSA, R. 1988. A invenção republicana. Rio de Janeiro: Vértice.

LEVINE, R. M. 1980. Pernambuco na federação brasileira, 1889-1937. A Velha Usina. Rio de Janeiro: Paz e Terra.

LOVE, J. L. 1975. O regionalismo gaúcho. São Paulo: Perspectiva.

1982. São Paulo na federação Brasileira 18891937. A locomotiva. Rio de Janeiro: Paz e Terra.

LYONS, T. 2004. Post-Conflict Elections and the Process of Demilitarizing Politics: The role of electoral administration. Democratization, London, v. 11, n. 3 , p. $36-62$. 
LUSTICK, I. S. 1996. History, Historiography, and Political Science: Multiple Historical Records and the Problem of Selection Bias. American Political Science Review, Los Angeles, v. 90, n. 3, p. $605-$ 618.

MARCHETTI, V. 2008. Governança eleitoral: o modelo brasileiro de justiça eleitoral. Dados, Rio de Janeiro, v. 51, n. 4, p. 865-893. Disponível em: http://www.scielo.br/pdf/dados/v51n4/03.pdf. Acesso em: 15.abr.2013.

MOZAFFAR, S. \& SCHEDLER, A. 2002. The Comparative Study of Electoral Governance Introduction. International Political Science Review, Thousand Oaks, v. 23, n. 1, p. 5-27.

MELO FRANCO, A. A.1973. Rodrigues Alves. Apogeu e declínio do presidencialismo. V. 2. São Paulo: USP.

NICOLAU, J. 2002. História do voto. Rio de Janeiro: J. Zahar.

2012. Eleições no Brasil. Do Império aos dias atuais. Rio de Janeiro: Zahar.

OROZCO HENRIQUEZ, J. J. 2007. El contencioso electoral, la calificación electoral. In: NOHLEN, D.; ZOVATTO, D.; OROZCO HENRIQUEZ, J. J. \& THOMPSON, J. Tratado de derecho electoral comparado de América Latina. Ciudad del México: Fondo de Cultura Económica.

PANG, E. S. 1979. Coronelismo e Oligarquias, 18891943. A Bahia na Primeira República Brasileira. Rio de Janeiro: Civilização Brasileira.

PASTOR, R. A. 1999. The Role of Electoral Administration in Democratic Transitions: Implications for policy and research. Democratization, London, v. 6, n. 4, p. 1-27, Winter.

PRZEWORSKI, A. 2010. Democracy and Limits of Self-Government. Cambridge (UK): Cambdrige University.

PORTO, W. C. 2000. Dicionário do voto. São Paulo:
Imprensa Oficial.

2002. O voto no Brasil. Rio de Janeiro: Topbooks.

2004. A mentirosa urna. São Paulo: M. Fontes.

RICCI, P. \& ZULINI P. J. 2012. Beheading, Rule Manipulation and Fraud: The approval of election results in Brazil, 1894-1930. Journal of Latin American Studies, Cambridge (UK), v. 44, n. 3, p. 495-521, Aug.

SADEK, M. T. A. 1995. A Justiça Eleitoral e a consolidação da democracia no Brasil. São Paulo: Konrad Adenauer.

SALES, C. 1983. Da propaganda à presidência. Brasília: UNB.

SCHUMPETER, J.A. 1988. Capitalismo, socialismo e democracia. São Paulo: Abril Cultural.

SOUZA, M. C. C. 1973. O processo político-partidário na República e a Revolução de 1930. In: MOTA, C. G. (org.). Brasil em perspectiva. São Paulo: Difel.

VALE, T. C. S. C. 2011. Pré-história e História da Justiça Eleitoral. Trabalho apresentado no XXVI Simpósio Nacional de História - ANPUH, realizado em São Paulo, de 17 a 22 de julho. Digit. Disponível em: http:/www.snh2011.anpuh.org/resources/ anais/14/1297170363_ARQUIVO_prehistoriae historaje.pdf. Acesso em: 15.abr.2013.

VIEIRA, J. 1980. A cadeia velha, memória da Câmara dos Deputados. Brasília: Senado Federal.

WIRTH, J. D. 1982. Minas Gerais na federação brasileira, 1889-1937. Rio de Janeiro: Paz e Terra.

ZIBLATT, D. 2009. Shaping Democratic Practice and the Causes of Electoral Fraud: The case of nineteenth-century Germany. American Political Science Review, Los Angeles, v. 103, n. 1, p. 1-21, Feb. Disponível em: http://politics.as.nyu.edu/docs/ IO/14562/Ziblatt.pdf. Acesso em: 15.abr.2013.

\section{OUTRA FONTE}

BRASIL. CÂMARA DOS DEPUTADOS. 2013. Anais da Câmara dos Deputados. Disponível em: http:// imagem.camara.gov.br/diarios.asp. Acesso em: 15.abr.2013. 